\title{
How Does Culture Affect International Business Between The United States and China?
}

\author{
Carolina Taylor \\ Emporia State University \\ Joyce Zhou \\ Emporia State University
}

For businesses in the United States it is crucial to understand the cultural differences between the United States and China. As found in previous studies with the Hofstede model, the two countries rate oppositely on multiple measures. This study researched how private corporations understand and utilize cultural training between the two countries. It also analyzed how trust, loyalty, and sales expertise are perceived between the two countries. Conducting interviews with global managers in a private company allowed for deductions regarding primary concerns with conducting business with China. Concerns regarding intellectual property and trust were main focuses in the results.

Keywords: International Business, China, Trust, Loyalty, Sales Expertise, Hofstede Cultural Dimensions

\section{INTRODUCTION}

Interactions are an integral function in international business; therefore, understanding how the cultures of different countries can affect the way the two countries interact is necessary. International business isn't limited to certain countries. However, in our current society, a significant amount of the international business that takes place in the United States occurs with China. Thus, analyzing how China differs in their business practices through their cultural aspects is vital for international corporations to have functioning business relationships. Many of the differences lay with the importance each country puts on concepts such as trust, sales experience, and loyalty. Each concept aids in creating a dependable relationship between businesses that can withstand over time. Since many businesses want to focus on developing long-term relationships, rather than short-term relationships, understanding how the individual characteristics of culture is key. 


\section{LITERATURE REVIEW}

International business is a complex topic that requires in-depth knowledge of the various areas, such as the laws, certifications, paperwork, locations, and cultures in business. If there is a lack of knowledge in any of the areas, one can ruin the relationship between two companies. Therefore, when considering participating in international business one must research and understand all factors. In general, the most undocumented and under-understood area in international business is culture. While culture is subjective and differs in each country, it can be detrimental to a business if not taken earnestly. Therefore, businesses must complete comprehensive research before embarking on international business.

\section{Hofstede Model}

Culture varies significantly between different countries. This can be shown through analyzing how the citizens place value on certain ideas or concepts. One example is how the Hofstede model uses aspects such as power distance, individualism, masculinity, uncertainty avoidance, long-term orientation, and indulgence. in their everyday lives to rate countries (Fan \& Zigang, 2004). In doing so, we can see where each country places value; thus, their tendencies when doing business. The model takes multiple aspects into consideration to end in a result that is well rounded. This can offer valuable insight into what countries and companies a business wants to do business with before initiating contact. Narrowing the viable options down allows for the company to have a better response to interactions.

\section{Power Distance}

The first category of the Hofstede model is power distance. Power distance refers to the way the way in which people in organizations accept and expect power to be allocated unevenly. This means that when power distance is high employees expect their superiors to have significant control over their job and the decisions being made. Whereas, in a society when power distance is low the amount of authority the employers possess will be lower. The United States received a low score of 40 and China received a high score of 80 on the Hofstede model (Fan \& Zigang, 2004). China's score is twice that of the United States which can lead to significant effects on the interactions between them. If a manager from either country addresses someone of lower ranking in the other country, it can result in uncomfortable situations.

\section{Individualism}

The second topic covered in the Hofstede model is individualism (verses collectivism). Individualism refers to the focus people place on themselves when trying to achieve goals either personally or professionally. Collectivism involves placing an emphasis on the group rather than the individual. China scored incredibly low with 20, while the United States scored extremely high with 91 (Fan \& Zigang, 2004). Since the difference is substantial it can cause complications when employees from either country must work in the opposite. "In tightly knit Chinese social organizations, people often see themselves as part of the group and pursue harmonious interpersonal relationships," (Liao, 2016). When working with United States organizations it can be difficult to communicate since those in the US are used to working independently. Therefore, an understanding must be reached on the level of dependence on others in the organization or deal.

\section{Masculinity}

The third aspect of the Hofstede model is Masculinity (and Femininity). These concepts are more difficult to analyze given the current emotion associated with them. However, they are still relevant to this study. Masculinity refers to the characteristics typically associated with men, whereas femininity refers to those associated with women. Men tend to be seen as more direct, forceful, and confrontational. Women on the other hand tend to be seen as indirect, fragile, and amicable. When researching, it was found that the United States is more masculine while China has more feminine tendencies (Fan \& Zigang, 2004). Understanding how the differences can interact can enhance the relationships between businesses. It also allows you to see what to avoid when working with that particular country. For example, when dealing 
with conflict Chinese managers prefer to handle the situation with aid from a third party to avoid larger problems; whereas, American managers prefer to use direct methods even if it leads to more problems (Fan \& Zigang, 2004). If a business doesn't understand the other's tendencies it can lead to tense situations. Conflict isn't the only area that can lead to demanding situations in international business, any situation if handled improperly can lead to these problems.

\section{Uncertainty Avoidance}

Uncertainty avoidance is the fourth category covered in the Hofstede model. Uncertainty avoidance represents a desire to avoid risks. When tested, it was found that China (30) scored higher than the United States (46) (Hofstede, Hofstede, \& Minkov, 2010). This can be important when operating a business that is risky in the United States because working with businesses in China might be hesitant. Therefore, allowing them to have all of the information associated with the deal should be told upfront and they should have the time necessary to make a solid decision. If they feel as though they are being rushed or won't receive required amounts of profits. Administrators in the United States, on the other hand, are willing to accept more risk if the potential benefits are large enough. In either country risk has a momentous affect on their decisions. Therefore, understanding their preferences is vital to potential business deals.

\section{Long-term Orientation}

The fifth category this paper will utilize is long-term orientation. This denotes an individual or organizations tendency to favor long-term goals over short-term goals. In this category China and the United States differ significantly. China scored 87 on the model in contrast to the United States 26 on the model (Fan \& Zigang, 2004). China looks for how their current actions and decisions will have effects on their long-term goals of the business. On the contrary, the United States focuses on how their current actions and decisions will result in a relatively quick payoff for the business. Each method has different advantages and disadvantages for the business. However, long-term and short-term orientation can be problematic if operating with the opposite without understanding. If one is long-term oriented, they tend to want to build a relationship that will be beneficial over time. Oppositely, if one is short-term oriented, they want a quick profit or deal without the relationship component.

\section{Indulgence}

The final category analyzed in this study is indulgence. Indulgence is the concept of allowing one's self to participate in something beyond the basic requirements for living or societal interactions. The United States scored a 68 in retrospect to indulgence, while China only scored a 24 (Hofstede, Hofstede, \& Minkov, 2010). This has significant impact on the way the different cultures perceive necessities differently. When analyzing the idea of luxury associated with indulgence there are multiple interpretations regarding luxury's importance in different cultures. A study found that the United States associate luxury with "exclusivity" and "prestigious", but not "conspicuousness". While, China associate's luxury with "conspicuous" and "extravagant", with the last adjective being "exclusive" (Godey, et al., 2013). This is important to understand how these concepts affect business interactions and the self-evaluations within each culture. The association with luxury for the United States is focused on something being rare or exclusive, which is linked to the material and societal ways we live and act. Therefore, as a society it brings indulgence into the workplace through actions such as smiling at customers to bring a level of indulgence to those who can't obtain luxury through status (Hofstede, Hofstede, \& Minkov, 2010). However, China's association with luxury is focused towards the status related to it and how it is shown. Therefore, indulgence isn't brought into the workplace, thus the lower score. 


\section{Foundation of Business Relationships}

Each aspect of culture is unique and can have significant negative effects on the business's relationships, but also to the overall international business prospects of the company. Reputations hold significant amounts of power when there is not a current working or personal relationship with a company. If a company has a reputation for being culturally insulting or negative in general, it will be difficult for it to continue in that international market. Therefore, businesses must focus on building those relationships. Building quality relationships can offer favorable outcomes, both in the short term and the long term (Jiang, Shiu, Henneberg, \& Naude , 2016). In business, many American companies focus on making short-term goals rather than long-term goals. However, Chinese companies prefer to build relationships that will benefit the business for the long-term (Fan \& Zigang, 2004).

To develop a long-term relationship, businesses must have full comprehension of the deal they are potentially operating with. As a result, communication or the exchange of information that is vital for the prospective parties must be handled appropriately to ensure cooperation (Jiang, Shiu, Henneberg, \& Naude , 2016). When the business interactions are between different countries or cultures communicating can be increasingly important. "With cross-cultural communication, the issue is not how to get rid of cultural differences, but rather how these differences can be used to increase productivity and new ways of solving problems," (Wall, 2013) While each culture has either own methods and preferences, when combined both cultures can be combined to produce a high functioning relationship.

\section{Trust}

To build long-term relationships in any business one must have a solid foundation to build on. Without this foundation the relationship will lack stability and reliability. One of the keys to a successful relationship in business is trust. Trust is the concept that allows for individuals or organizations to rely on a business to fill their promises (Newell, Wu, Leingpibul, \& Jiang, 2016). In business negotiations are handled through contracts; however, if one does not believe the other business is reliable, they will not want to be involved, with or without a contract. Therefore, being trustworthy in your business practices sets the stage for continued interactions with potential and current customers. Overall, in a study completed by Troy Heffernan it was found that all forms of trust from the first to the final interaction can have significant impacts on the longevity of the business relationship (Heffernan, 2004).

\section{Loyalty}

Another key to long-term business relationships is the loyalty shown between the two businesses. Loyalty is being faithfully committed to the best interest of both parties and the continuation of the relationship (Newell, Wu, Leingpibul, \& Jiang, 2016). When in business, it is important to know that both parties are dedicated to seeing prosperous outcomes for both, rather than only themselves. This increases to value of the overall relationship and allows for the businesses to communicate more openly about potential problems. Thus, amplifying the social satisfaction through interacting with that individual company. Social satisfaction is the satisfaction, both on a business and personal level, found in working with an exchange partner (Jiang, Shiu, Henneberg, \& Naude , 2016). When business enjoy interacting with another business, they will typically continue to execute transactions with them.

\section{Sales Expertise}

The final major key to business relationships is the sales expertise each business has. Sales expertise is the knowledge, skill, or competency that an individual or business retains (Newell, Wu, Leingpibul, \& Jiang, 2016). While a business could be operating on a large scale, they might not possess the knowledge, skill, or competency necessary to be successful. Therefore, when operating any form of business there must be a substantial amount of all three to be a credible company. This also allows increases the abilities of the company to be ahead of changes in the field or innovative technology. Being able to understand and increase the success rate of a product or service can have considerable effects of the amount of business they receive. 


\section{METHODOLOGY}

This study was a qualitative study which focused on how the differences in cultures between the United States and China affect business. This company was selected based off of the previous knowledge of its interaction with China in both production and sales. The company is headquartered out of the Midwest. Said company has 8 additional manufacturing facilities and 3 technology centers throughout the United States, Mexico, Europe, and Asia. For the past 10 years they have had a production facility located in China, that was initially established and developed by those localized in the facility utilized in this research. Since the expansion to the Chinese business market this facility has had significant interaction with the production center and customers in China. It also has been utilized in the past for its experience with culture relative to business in previous research completed by the researcher.

\section{Participants}

Initially, the plant manager was contacted for permission to complete this research. They then provided the name of a manager who had significant knowledge of who had experience with China. Said manager then provided a prepared list of middle-level managers who fit the requirements to participate in this study. A total of 6 middle-level managers were interviewed over their expectations, perceptions, and understanding of international business between the United States and China. This amount was limited to allow the research to be accomplished in a set time limit. Participants had an age range of 34 to 57, with an average of 48.67. The average length of experience from those participants was 18.17 and ranged from 7 to 25 . This allowed for analysis over the changed in perception with age and experience levels. Due to the limitations of this facility all of those interviewed were male. This limited the abilities to analysis how gender might affect perceptions within international business with China.

TABLE 1

\section{PARTICIPANT DEMOGRAPHIC INFORMATION}

\begin{tabular}{|lll|}
\hline Participant & Age & Experience \\
\hline 1 & 57 & 20 \\
\hline 2 & 54 & 25 \\
\hline 3 & 57 & 25 \\
\hline 4 & 47 & 12 \\
\hline 5 & 34 & 7 \\
\hline 6 & 43 & 20 \\
\hline
\end{tabular}

\section{Procedures}

Once participants were selected the interviews were completed at the facility during their normally scheduled time at work in July of 2018. This allowed for convenience for those being interviewed, as it did not significantly withdraw them from them responsibilities at their job. Since it was based on qualitative methods it utilized an interview with open-ended questions. This allowed for the participants to share their generalized perceptions of the areas of focus. As a result, the researcher was able to deduce themes mentioned throughout all 6 interviews and their significance levels. During the interview's recordings were taken to aid in transcribing the information gathered and to assure accuracy of notes taken.

\section{Analysis}

Once all the data was collected it was processed and complied into categories to aid in the analyzing stage of research. The main focus of the interviews was trust, loyalty, and sales expertise. While there are 
several aspects that can be evaluated within business, the topics were chosen to make the study plausible for the timeline. These concepts are also the generalized foundation for business interactions in the United States; therefore, utilizing them in the context of the Chinese business market allowed for differences to be derived from the interviews.

\section{RESULTS}

Data was collected through open-ended questions allowing for the respondents to expand on areas they felt were important. Completing the interviews in this format provided distinctive themes as to what to consider within international business with the US and China. It also provided an opportunity for the respondents to describe relevant examples they have experienced in their own encounters with the Chinese business market.

\section{Trust}

As previously mentioned in the literature review, trust is a key factor within the success of business relationships in the United States. Therefore, we wanted to analyze how different cultures may have different perceptions of this concept. Specifically, we focused on China based off the stigma associated with the concept. The participants were asked what significance they placed on trust within the context of completing business with China. The respondents separated the concept of trust into 2 categories, individual and business. They stated that they maintain the same level of trust with the people they work with in China as consistent with those in America. However, when referencing the trust in business, they stated that it is difficult to allocate. Two out of the six (33.3\%) interviewed stated that trust is not a factor when handling business with China. Contrary, four out of the six $(66.7 \%)$ stated that they consider trust a major component in business with China.

\section{Sales Expertise}

Technical knowledge of a product or how it is utilized to perform a task is sales expertise. Sales expertise is highly recognized, appreciated, and pursued within the American business market; therefore, we wanted to evaluate how the Chinese business market varied. The participants were asked what significance they placed on sales expertise within the context of completing business with China. The respondents stated that the concept of sales expertise in business transactions varies significantly between the United States and China. Many referenced that the US focuses on technical knowledge of products for business deals. $83.3 \%$ stated that the Chinese business market focuses on relationships rather than the technical skills associated with selling products in the US.

\section{Loyalty}

Loyalty is the concept of being faithful to another entity and maintaining beneficial relationships for each entity. This is relative to the longevity of business relationships between companies and can be positive or negative depending on the significance placed on it. The participants were asked what significance they place on loyalty within the context of completing business with China. 50\% of the respondents stated that business transactions with China are driven by price and cost rather than any loyalty to a company. All 6 respondents acknowledged that loyalty is difficult to build or simply not present in the Chinese business market.

\section{Ranking}

After collecting the perceptions on trust, sales expertise, and loyalty the participants were asked to rank the three concepts from most important to least important. This allowed for the researchers to evaluate the differences and significances between each concept. When asked how they would rank the importance of trust, sales expertise, and loyalty four of the six $(66.67 \%)$ respondents stated it as trust, sales expertise, and loyalty. One (16.67\%) individual stated that the order was trust, loyalty, and sales expertise. For one (16.67\%) respondent sales expertise was the only relevant concept. 


\section{Cultural Training}

Cultures are complex areas that generally require some form of training to prepare employees and avoid significant damage to the company. The respondents were asked if they received any form of cultural training and to what degree. One individual stated that they did not receive or require cultural training. Four of the six stated that they received informal cultural training through their employer. One respondent stated that he received only informal training through the employer, but that he also received formal cultural training during his education. The respondents were asked if they had any acknowledge or experience with the Hofstede Model, as it is used to base this study and to understand cultures. None of those interviewed had any knowledge of what the model was. They were also asked if they felt businessto-business relationships varied between the US and China, to which every respondent stated yes. The purpose of this was to see if statements used in educational situations for business students translated into the employment experience of these individuals.

\section{Intellectual Property}

While intellectual property was not specified within the questions asked to the respondents, it was present through out the interviews. Participants stated that it is a consistent concern when interacting with Chinese companies.

\section{DISCUSSION}

Overall, the results corresponded to my expectations of culture in international business with the United States and China based off previous information gathered. However, there were key themes present in the interviews that were not predicted when outlining this research. Therefore, this section will analyze the data collected during the research regarding the significance of the results and deductions of the differences found.

\section{Trust}

Trust is a heavily discussed topic in relation to business with China due to both professional, personal, and political views. Therefore, understanding what affect it can have on the success of a business relationship can be vital to companies. It was important for the respondents for there to be a distinction between the levels of business and individual regarding trust. This signified that weight of trust between individuals is consistent with working with other US based businesses. In separating trust into the category of business it allowed for respondents to state that it was not present without contradicting the importance of it overall. However, the data regarding the significance of trust was impacted by outside influences such as the government. Certain products produced in the facility are heavily governmentally regulated materials. When a high level of regulation is present in business, the companies available to sell your products to have already been through a rigorous acceptance process. Therefore, trust is not a main consideration for the individuals that handle those interactions. This could have altered the conclusions or significance found within the concept of trust.

\section{Sales Expertise}

When discussing the concept of sales expertise, the majority of those interviewed stated that the Chinese business market is focused on relationships rather than sales expertise. One way this is accomplished is through having a local agent in China on the company's behalf. Therefore, being able to build a relationship with an agent is vital in the progress of a business relationship and transaction in China. The success of your business transaction relies heavily on that relationship being well developed. As a result, many companies request to have someone of their own nationality to act as a liaison. This allows for a level of "protection" within the transaction by having someone who knows the laws and needs for Chinese businesses. Since the Chinese government does have different laws in place this also can provide a sense of assurance for companies in the US if they have someone more familiar with it in the interaction. 


\section{Loyalty}

Contrary to the original hypothesis of loyalty in business, loyalty has substantially low impact on the overall interactions between businesses. While it can be a driving force behind American businesses and customers, it is difficult to develop within the Chinese business market for American companies. Therefore, businesses must strive to excel in other areas of business in order to be successful. One focus mentioned by half of the respondents was the importance of price. This proposes that businesses must analyze the cost of their product in comparison to similar ones in China before officially making a proposal. If the cost is too high compared to those in China or elsewhere, the Chinese company will not pursue it future. Cost should be sought out rather than loyalty in international business with China.

\section{Ranking}

Through evaluating how managers ranked trust, sales expertise, and loyalty we were able to draw conclusions on the importance of each concept. Generally, it was shown that while trust was difficult to develop with Chinese companies, it was the most important to managers. Since trust is such a large focus in the American morals it is probable that it carried through based off their personal perceptions of it in their daily lives. Similarly, the differences between sales expertise and loyalty were distinctive except for one individual. This individual stated that for his position in the business sales expertise was not a viable method for conducting business with China. Oppositely, one individual responded that the only important concept for his area was sales expertise. This is largely since his products are heavily regulated by the government, as previously mentioned.

\section{Cultural Training}

Overall, it was found that informal cultural training was the focus for those at this company. While informal training limits the cultures covered and the depth of the training, it offers brief highlights of vital information. This shows that the company does understand the significance of culture in business and addresses it to an extent. This facility has reduced interactions with international business in relation to the headquarters. Therefore, other members of the company if different facilities could receive different levels of training depending on their position, location, and management.

\section{Intellectual Property}

One concern repeatedly expressed during the interviews was the concept of intellectual property and its significance/implication in business. If intellectual property rights are not enforced properly it can lead to monumental economic impacts through lost profits on businesses (Brander, Cui, \& Vertinsky, 2017). While the losses can be limited depending on the situation it opens the door for more extreme versions of infringements. It has been found that losses due to infringements will only continue to worsen regarding China, even though laws are increasing a result of the improved technologies and focus on innovation (Brander , Cui, \& Vertinsky, 2017). Therefore, businesses must have encryptions and locking systems in place on devices used in international business to ensure the protection of intellectual property.

\section{IMPLICATION}

In our society, international business between the United States and China has become increasingly important for long term stability for businesses in the United States. Therefore, understanding what is key to developing the relationships for international business is vital. One major factor when operating internationally is the culture in the country you're working in, since every country has distinctly diverse cultures. If one does not do the appropriate research on how to conduct business with others, particularly in other countries, their success rate will be very small and their chances of harming their reputation are significant. Every country has distinctive characteristics that make it unique; therefore, every business must analyze their actions in retrospect to the others point a view. By studying how these two countries should interact in business settings it will allow for current and future members in business to have a

Journal of Marketing Development and Competitiveness Vol. 13(3) 2019131 
better understanding of the significance of culture. Overall, increased amounts of research can result in a better relationship between the two businesses and eventually the two countries in the future.

\section{CONCLUSION}

Culture has significant impacts on international business, both positively and negatively. Therefore, when operating an international business companies must analyze how they handle situations with additional attention and precaution than they would with another company in the United States. This is especially valid when completing business with China, as a result of differences between the cultures. As a result, business should implement cultural training with individuals functioning in positions of international business to avoid potential harm to the company. Much of the business market in China is directed towards having strong relationships and low costs. Being able to combine and improve on these points offers a significant advantage when looking at expanding into their market. In order to do so, companies should understand how trust changes regarding China's business market, but also the importance it plays in the relationship aspect of business. However, businesses also need to analyze the risk associated with intellectual property and recognize that trust does not translate into every matter in international business. International business with China is continually expanding due to the substantial growth present in their market; therefore, recognizing the culture of those within it can have considerable impacts on the success of the interaction.

\section{REFERENCES}

Brander, J. A., Cui, V., \& Vertinsky, I. (2017). China and intellectual property rights: A challenge to the rule of law. Journal of International Business Studies, 48, 908 - 921. doi:10.1057s41267-017$0087-7$

Fan, P., \& Zigang, Z. (2004). Cross-cultural Challenges when Doing Business in China. Singapore Management Review, 26(1), 81-90.

Godey, B., Pederzoli, D., Aiello, G., Donvito, R., Wiedmann, K.-P., \& Hennigs, N. (2013). A crossculural exploratory content analysis of the perception of luxury from six countries. Journal of Product and Brand Management, 22(3), 229-237. Retrieved from https://www.emeraldinsight.com/doi/abs/10.1108/JPBM-02-2013-0254

Heffernan, T. (2004). Trust formation in cross-cultural business-to-business relationships. Qualitative Market Research: An International Journal, 7(2), 114-125. doi:10.1108/13522750410530020

Hofstede, G., Hofstede, G. J., \& Minkov, M. (2010). Cultures and Organizations: Software of the Mind. McGraw Hill.

Jiang, Z., Shiu, E., Henneberg, S., \& Naude, P. (2016). Relationship Quality in Business to Business Relationships - Reviewing the Current Literatures and Proposing a New Measurment Model. Psychology \& Marketing, 33(4), 297- 313. doi:10.1002/mar.20876

Liao, K.-H. (2016). Impact of Traditional Chinese Culture on Business-to-Business Relationship Marketing and Service Firm Performance. Journal of Business-to-Business Marketing, 23, 277 291. doi:10.1080/1051712X.2016.1250594

Newell, S. J., Wu, B., Leingpibul, D., \& Jiang, Y. (2016). The importance of corporate and salesperson expertise and trust in building loyal business-to-business relationships in China. Journal of Personal Selling \& Sales Management, 36(2), 160-173. Retrieved from http://dx.dio.org/10.1080/08853134.2016.1190656

Wall, W. P. (2013). Is Cross-Cultural Management the Key to Success in Global Healthcare Competition. International Journal of Business and Information, 8(1), 70-95. 